\title{
Experimental Study on the Effects of Tightening on the Performance of Thermoelectric Generator for Human Body Heat Harvesting
}

\author{
TanKuan You ${ }^{1}$, Hassan Mohamed ${ }^{2}$, Madihah Mujaini $^{3}$ \\ ${ }^{1}$ College of Engineering, Universiti Tenaga Nasional,Malaysia, kytan0127@ gmail.com \\ ${ }^{2}$ Institute of Sustainable Energy, Universiti Tenaga Nasional, Malaysia,mhassan@uniten.edu.my \\ ${ }^{3}$ College of Engineering, Universiti Tenaga Nasional, Malaysia, madihah@uniten.edu.my
}

\begin{abstract}
Thermoelectric generator (TEG) has been researched for quite some time in harvesting human body heat to generate electricity as human body generates heat naturally and continuously through metabolism process. In this study, the effect of thermal contact between thermoelectric generator and the heat source from human body is studied through the tightening of TEG attachment onto the skin. Several sets of experiments are conducted on three different body part locations, namely forehead, forearm, and wrist of different individuals of different genders by considering parameters such as surrounding temperature, skin temperature, output voltage and current. The values of power generated from the TEG are calculated and analysed.Results show that the tightening of the TEG attachment to the skin surface increases the thermal contact and shows the most significant increment in power generated on more flexible skin location especially at the upper arm of female with $280 \%$ increase in power output. However, forehead remains as the highest power generator with a power output of $3414 \mu \mathrm{W}$ after tightening.
\end{abstract}

Key words: Energy harvester, thermoelectric generator (TEG), tightening, waste heat.

\section{INTRODUCTION}

The rapid depletion of fossil fuels and their adverse effect towards the environment has led to the global concern on the development of alternative renewable energy. In recent years, thermoelectric power generation from waste heat has been considered as a promising alternative green and clean energy $[1,2]$. Some of the advantages of thermoelectric generator (TEG) devices over traditional power generation include compact in design, no moving parts, silent in operation, longer operational time and environmental friendly. TEG has also been researched for quite some time in harvesting human body heat to generate electricity as human body generates heat naturally and continuously through metabolism process. A recent experimental study by Rosli and Mohamed [3] shows that the use of TEG in harvesting human body heat to generate electricity is feasible in Malaysia. The experiment was conducted on two human samples under different human activities on different location of the body and showed that a specific body part generates the maximum power. However, the energy converted is small due to various energy losses.
When the TEG is placed on the body, thermal contact resistance exists between the skin and the TEG due to the curve and rough surface of skin. While skin, in its natural state, is soft and deformable with pressure, the contact resistance at the skin-TEG interface is closely related to the pressure exerted on the surface [4]. It is found that the heat transfer coefficient increases with pressure, with the highest heat transfer coefficient is at the forearm while the lowest is at the forehead as shown in Error! Reference source not found.

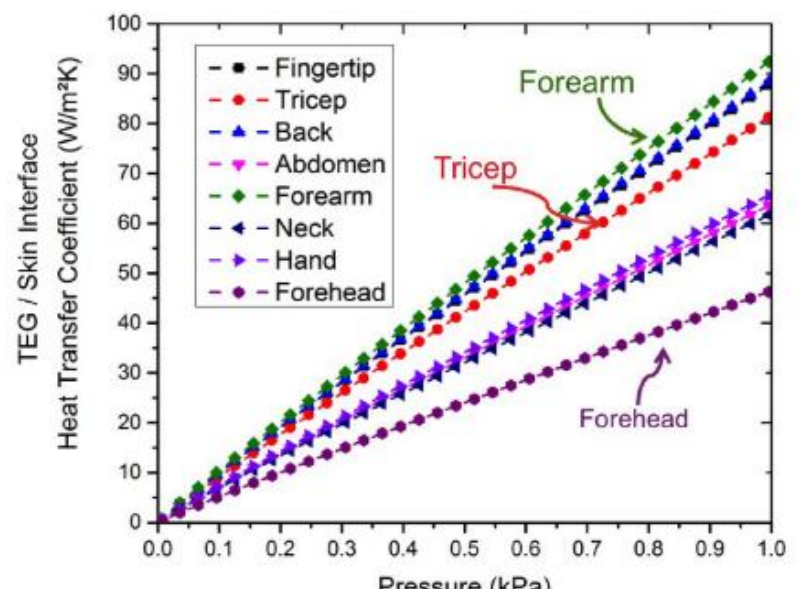

Figure 1: Heat transfer coefficient of skin-TEG interface at varying pressure and locations of the body [4].

Improvements in energy harvesting using TEG may promote various practical TEG applications such as e-health monitoring devices[5] and body heat harvesting from aircraft passengers[6].

\section{METHODOLOGY}

To determine the optimum location of human body for heat harvesting, several tests werecarried out in a controlled laboratory setting with constant ambient air temperature of $28^{\circ} \mathrm{C}$, to characterize the response of TEG with and without tightening effect. Tests were performed with basic TEG on three different body parts, which are forehead, forearm, and wrist. These loctions were selected because they are suitable for the placement of TEG without causingdiscomfort while performing daily activities. Each test, without any further tightening of the TEG strap around the body parts, was performed on three different modes of human activities, 
which are resting, walking and running. After completing all these tests, the similar experiments were repeated with basic TEG again but this time to maximize its power generation the strap was tightenedto increase contact between the TEG and human skin. The detailed process flow of the experiment is illustrated in Error! Reference source not found..

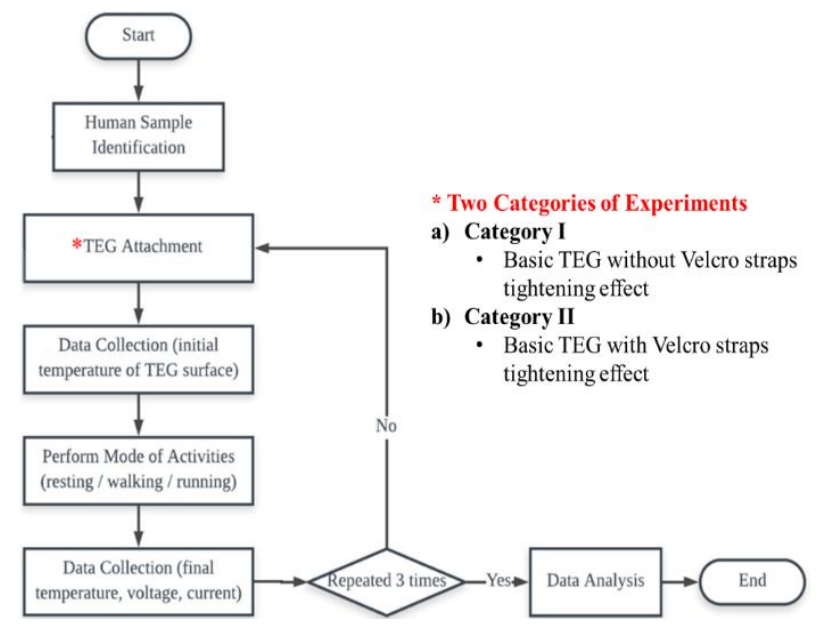

Figure 2: Process flow chart for TEG experiment

\subsection{Optimizing the Lighting System}

The thermoelectric generator (TEG) module was inserted into a 3D printed casing as shown inError! Reference source not found.. The Velcro straps were attached onto the side casing slots. Type-K thermocouples were attached firmly on the top and bottom of the TEG to obtain the temperatures of both surfaces (hot and cold sides).

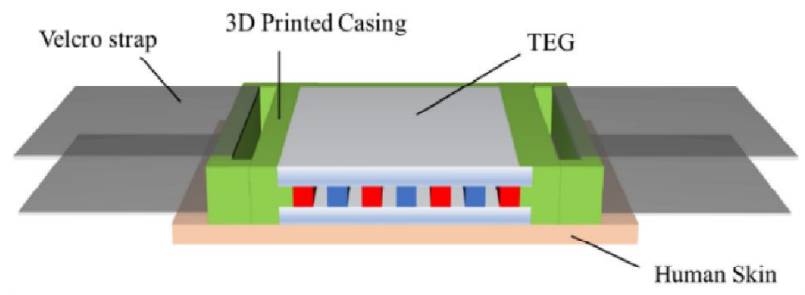

Figure 1: Illustration of basic TEG device assembly

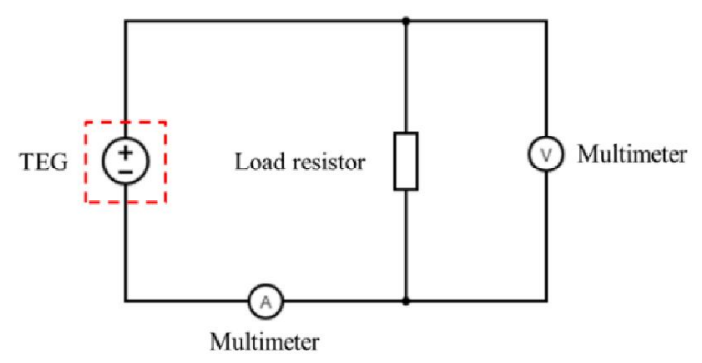

Figure 2: Circuit diagram for voltage and current measurement
The total number of test participants for the experiment was 6 , which consisted of 3 males and 3 females. The participants werewithin the age group of 18 to 25 years old. The height, weight and body mass index of every individual were recorded. The preassembled TEG device was placed on the targeted part of human skin. It was wrapped and secured nicely by the Velcro straps, firmly around the body part location without any further tightening or pressure applied. The scale reading on the strapwas marked and recorded.

For the experiment, there were three different types of activities, namely resting, walking and running. The test participants started with resting mode measurement by simply sitting on a chair. As in walking and running modes, the participantwalked and ran with speed levels of $20 \mathrm{~min} / \mathrm{km}$ $(0.833 \mathrm{~m} / \mathrm{s}$ or $3 \mathrm{~km} / \mathrm{hr})$ and $10 \mathrm{~min} / \mathrm{km}(1.667 \mathrm{~m} / \mathrm{s}$ or $6 \mathrm{~km} / \mathrm{hr})$, respectively. Each activity was carried out for 10 minutes and the readingsof temperatures, voltageand current were recorded. Each activity was repeated for 3 times to obtain an average reading. A five minutes break period was provided between tests to allow the temperatures of the skinand TEG return to their normal temperatures.

The temperatures on both sides of the TEG device, cold and hot surfaces, were measured and recorded by the thermocouples, before and after every activity to determine the temperature difference. The digital multimeter was used to measure the voltage and the current produced by the TEG after each activity. The data were then tabulated and analyzed.The experiment was repeated by further tightening the Velcro strap by $2 \mathrm{~cm}$ from the initial marking. The performance of TEG, which is the power output,can be calculated using the product ofmeasured voltage and current.

\section{RESULTS AND DISCUSSION}

The raw data were tabulated and generated into graphs. Error! Reference source not found. illustrates the effect of $2 \mathrm{~cm}$ tightening on the power output from basic TEG at different body locations of male at rest, during walking and running modes.Based onError! Reference source not found., the tightening of the TEG attachment to the body parts at rest has increased the overall power output as compared to the basic configuration. By comparing the different body locations, upper arm had the largest percentage increase of $40.9 \%$ in power output, from $320 \mu \mathrm{W}$ to $451 \mu \mathrm{W}$.

During walking and running modes, the upper arm has a larger increase in power output as compared to the wrist and forehead. The power generated from upper arm during walking has increased by $18.3 \%$, from $451 \mu \mathrm{W}$ to $533 \mu \mathrm{W}$ with tightening effect. At running mode, the power generated from upper arm has increased by $41.6 \%$, from $823 \mu \mathrm{W}$ to $1165 \mu \mathrm{W}$. 
TanKuan You et al., International Journal of Emerging Trends in Engineering Research, 8(5), May 2020, 1937 - 1940

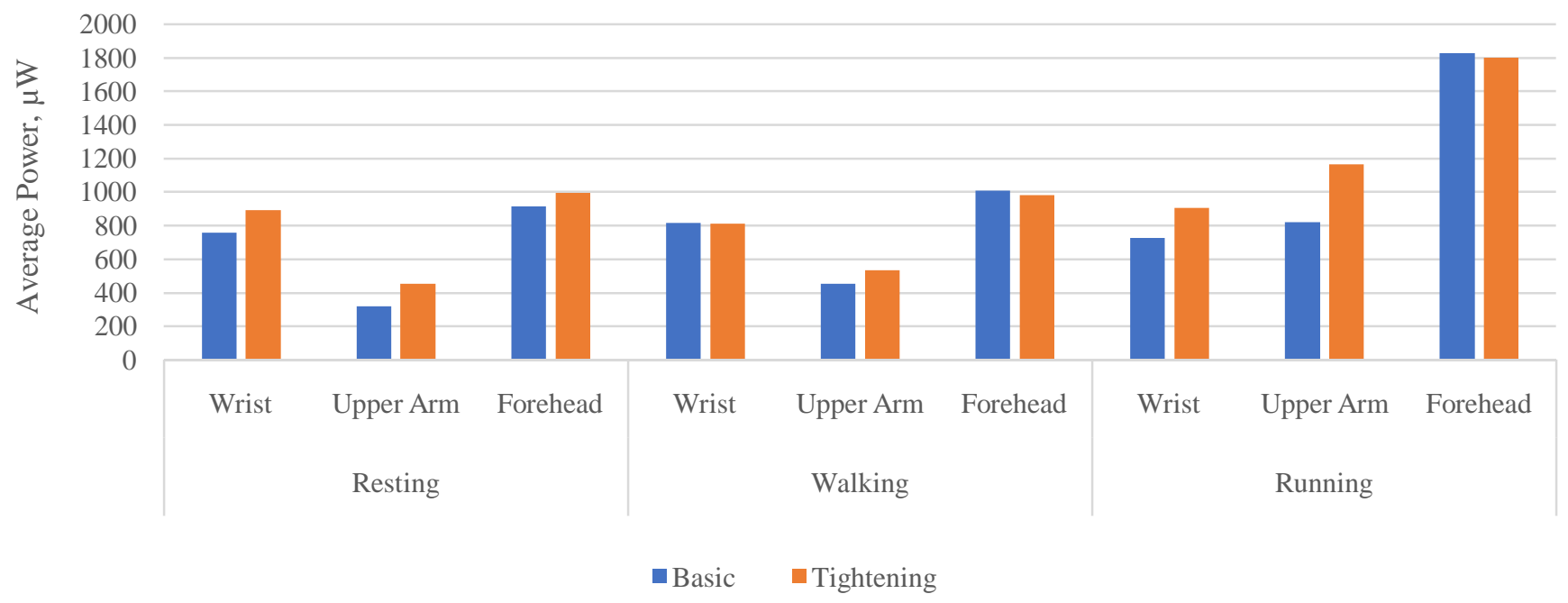

Figure 5: Effect of tightening on basic TEG (male)

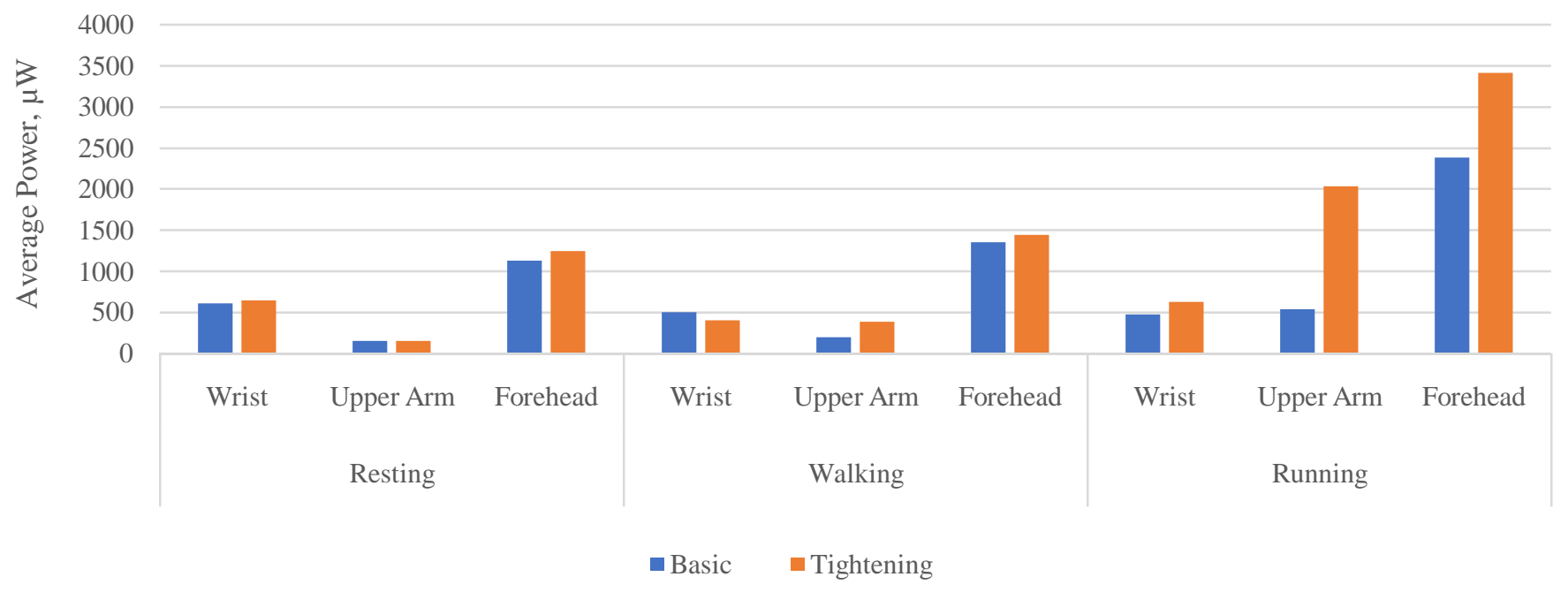

Figure 6: Effect of tightening on basic TEG (female)

Error! Reference source not found. illustrates theeffect of $2 \mathrm{~cm}$ tightening on the power output from basic TEG at different body locations of female at rest, during walking and running modes.Referring to Error! Reference source not found., the tightening attachment hasminimal impact in percentage on the power generated from different body parts of female, except the upper arm. During walking activity, the average power generated from upper arm after tightening effect was $381 \mu \mathrm{W}, 90.1 \%$ higher than the power generated without tightening effect, which is around $200 \mu \mathrm{W}$.

The effect of tightening on the power generated during running mode was very significant, especially on the upper arm and forehead. The average power generated from upper arm of female during running has increased by $280 \%$, from $536 \mu \mathrm{W}$ to $2038 \mu \mathrm{W}$ after tightening. The average power output from forehead during running has also increased by $43 \%$, from $2388 \mu \mathrm{W}$ to $3414 \mu \mathrm{W}$.
From the results of both male and female categories, the tightening of TEG has the most significant effect on the power outputgenerated from the upper arm than other tested locations. Basically, when the device was further tightened to the human body, the thermal resistance between the skin and TEG would reduce as the skin could be deformed and air gap was eliminated. Hence, the heat transfer would increase and more power would be generated at the location where the skin was more flexible especially at the upper arm. The data were also in agreement with [4]. It also can be seen that forehead has always generated the highest powerbecause of its highest average skin temperature, hencecausing larger temperature difference between the cold and hot surfaces of TEG.

It was also observed that the effect of tightening is more significant to the female category. This might be due to the softer and more flexible skin textures of female participants who have more fat than male participants, allowing more 
deformation and elimination of air gaps which further reduces the thermal resistance between the skin and TEG.

\section{CONCLUSION}

This study is beneficial in improving the performance of TEG in harvesting human body heat to generate electricity. The tighteningeffect is more significant to female participants Based on the results, the average power generated from upper arm of female during running had increased by $280 \%$, from $536 \mu \mathrm{W}$ to $2038 \mu \mathrm{W}$ after tightening. This is the highest percentage increase obtained during the experiment. However, forehead maintains as the highest power generator as it has the largest temperature difference between the cold and hot surfaces. Overall, the highest power outputafter tightening is $3414 \mu \mathrm{W}$, whichwasobtained from the forehead of female participants during running.

\section{ACKNOWLEDGMENT}

The authors would like to acknowledge UNITEN for funding this work under the BOLD 2025 PHASE 2 Research grant (10436494/B/2019073).

\section{REFERENCES}

[1] [X. F. Zheng, C. X. Liu, Y. Y. Yan, and Q. Wang, "A review of thermoelectrics research - Recent developments and potentials for sustainable and renewable energy applications," Renew. Sustain. Energy Rev., vol. 32, pp. 486-503, Apr. 2014, doi: 10.1016/j.rser.2013.12.053.

[2] D. M. Rowe, "Thermoelectrics, an environmentally-friendly source of electrical power," Renew. Energy, vol. 16, no. 1-4, pp. 1251-1256, Jan. 1999, doi: 10.1016/S0960-1481(98)00512-6.

[3] N. Rosli and H. Mohamed, "Experimental Study on the Use of Thermoelectric Generators in Harvesting Human Body Heat," Int. J. Eng. Technol., vol. 7, pp. 264-269, Nov. 2018, doi: 10.14419/ijet.v7i4.35.22744.

[4] F. Suarez, A. Nozariasbmarz, D. Vashaee, and M. C. Öztürk, "Designing thermoelectric generators for self-powered wearable electronics," Energy Environ. Sci., vol. 9, no. 6, pp. 2099-2113, 2016, doi: 10.1039/C6EE00456C.

[5] S. K, "E-Health based Patient Surveilling Device," Int. J. Emerg. Trends Eng. Res., vol. 8, pp. 792-796, Mar. 2020, doi: 10.30534/ijeter/2020/30832020.

[6] S. Salim and F. Romli, "Factorial Study on Seated Aircraft Passengers' Body Heat Harvesting," Apr. 2020, doi: 10.30534/ijeter/2020/60842020. 